\title{
REBEN: 70 ANOS NA CONSTRUÇÃO SOCIAL DO CONHECIMENTO DA ENFERMAGEM NO BRASIL
}

A Enfermagem é um campo de atuação profissional implantada a partir da segunda década do século XX e consolidada, ao longo de cerca de oitenta anos, como resultado do trabalho competente, perseverante e dedicado de milhares de pessoas e instituições comprometidas com o desenvolvimento intelectual, político, ético e econômico-social do conjunto de profissionais e da prática de enfermagem, tendo em vista, a oferta de serviços de enfermagem de qualidade e acessível a todas as pessoas, grupos e classes sociais, que demandam por ações/cuidados de enfermagem, no campo da promoção e proteção à saúde, prevenção e identificação precoce de doenças, no tratamento do agravos à saúde e na reabilitação, no contexto da produção de serviços de saúde no Brasil.

A implantação e a consolidação do Projeto Político-Profissional da Enfermagem Brasileira é produto/ resultado do desenvolvimento alcançado pelos seguintes espaços sociais, que dão sustentação à profissão no Brasil: qualificação dos profissionais; regulação da prática que é mediada pela escola, mercado e processo de trabalho, produção de conhecimentos e tecnologias, ética e a organização da categoria.

A Revista Brasileira de Enfermagem - REBEn tornou-se um patrimônio da Enfermagem Brasileira, considerando o papel fundamental que vem desempenhando, numa trajetória de lutas e conquistas, pelo desenvolvimento técnico-científico, ético, organizativo e na construção histórica da Enfermagem no Brasil.

A REBEn foi construída por muitos personagens/atores que deram vida e humanidade ao processo do cuidar de pessoas e/ou grupos sadios ou enfermos, de atuar na formação de novas gerações de profissionais, de comprometer-se com a prática da pesquisa e do exercício da busca e da descoberta, com o intuito de promover novos conhecimentos e tecnologias fundamentais ao desenvolvimento técnico-político, ao reconhecimento social e à legitimação desta profissão em diferentes momentos de sua história.

Este número temático de comemoração dos 70 anos da REBEn resgata um pouco da contribuição de alguns desses atores que participaram da construção social de uma política de pesquisa e pós-graduação para a área de Enfermagem, a partir da grande iniciativa de criação e consolidação dos ANAIS/REBEn.

A Revista tem se afirmado, no decorrer de sua história, como um recurso estratégico no processo de produção e difusão de conhecimentos e de novas tecnologias na área da Enfermagem; e dessa forma, tem participado do processo de (trans) formação permanente do modelo de prática profissional; possibilitando o crescimento qualitativo da particip-ação da Enfermagem na produção de serviços de saúde; o desenvolvimento da autonomia técnico-política; a ampliação da visibilidade da Enfermagem como serviço essencial na saúde e na expansão do seu papel e competências na sociedade.

É essa história, bem sucedida, que tenho o prazer de compartilhar com todos os meus companheiros de jornada no trabalho da Enfermagem/ Saúde.

Quero convidá-los a celebrar os setenta anos de existência da REBEn, que possibilitaram a gênese da Enfermagem como prática científica no Brasil, produtora de conhecimentos essenciais que se concretizaram em cuidados capazes de responder às demandas sociais por serviços de enfermagem/saúde de qualidade, que são parte dos avanços da sociedade pela conquista da qualidade de vida e da promoção à saúde.

E a REBEn, abrindo os caminhos da produção científica para a Enfermagem Brasileira, registra o resultado de estudos, pesquisas, análises e reflexões que contextualizam e recontextualizam a prática de Enfermagem, no seu processo histórico. Participando hoje, em conjunto com um grande número de revistas científicas da Enfermagem, da construção de um novo paradigma que respeite a complexidade da realidade dos problemas de saúde no que se refere ao campo específico da Enfermagem, visando a produção de cuidados de enfermagem que associem, na experiência humana do cotidiano da prática, a técnica e a emoção, a razão e a intuição, a ciência e o sonho/imaginação/criação de fazer, a cada dia, uma Enfermagem melhor, comprometida com a busca constante de uma ética da solidariedade entre os humanos, muito bem traduzida nas palavras do poeta João Cabral de Melo Neto, quando escreveu "Um galo sozinho não tece uma manhã, ele precisará sempre de outros galos".

${ }^{1}$ Professora do Departamento de Enfermagem da UFRN. Presidente da Associação Brasileira de Enfermagem (Gestão 